\title{
Desempenho de Cordeiros Texel x Bergamácia, Texel x Santa Inês e Santa Inês Puros, Terminados em Confinamento, Alimentados com Casca de Café como Parte da Dieta ${ }^{1}$
}

\author{
Iraides Ferreira Furusho Garcia², Juan Ramón Olalquiaga Perez ${ }^{3}$, Júlio César Teixeira ${ }^{4}$, \\ Cristina Maria Pacheco Barbosa ${ }^{5}$
}

\begin{abstract}
RESUMO - O objetivo deste trabalho foi avaliar o desempenho de cordeiros e cordeiras cruzas Texel x Bergamácia (T x B), Texel x Santa Inês (T x S) e Santa Inês (SI) puros. Trinta e seis animais foram confinados individualmente, durante um período de 50 dias, recebendo, além de silagem de capim elefante, três dietas: $\mathrm{A}=$ sem casca de café (controle), $\mathrm{B}=$ com casca de café in natura e $\mathrm{C}=$ com casca de café tratada com uréia e grão de soja moído. Os animais foram abatidos com idade média de 180 dias. Consumos de matéria seca (CMS), proteína bruta (CPB) e fibra em detergente neutro (CFDN), conversão alimentar (CA), peso final (PF), ganho de peso diário (GPD), peso de abate (PA), diferença de peso devido ao jejum (DPJ), conteúdo do aparelho digestório (CAD) e peso do corpo vazio (PCV) foram avaliados. A utilização de casca de café na dieta, tratada ou não, não influenciou os consumos de MS, PB, PF, GPD, CA, PF, GPD, PA, DPJ, CAD e PCV. O consumo de FDN aumentou com a utilização da casca de café, sendo menor para os animais que consumiram a dieta contendo casca de café tratada com uréia. Os animais cruzas T x B e T x S apresentaram menores consumos MS, PB e FDN e maiores PF, PA, CAD e PCV, comparados aos cordeiros SI. Não foi observada diferença entre os grupos genéticos para CA, GPD e DPJ, apesar dos valores ligeiramente maiores, mas não-significativos, para CA e GPD dos cordeiros T x B e T x S. Os machos apresentaram valores inferiores de consumos de MS, PB, FDN e CA e superiores para PF, GPD, PA e PCV que femeas. Machos e fêmeas mostraram-se semelhantes para DPJ e CAD.
\end{abstract}

Palavras-chave: alimentação, desenvolvimento, grupo genético, ovinos

\section{Performance of Texel x Bergamácia, Texel x Santa Inês and Purebred Santa Inês Lambs, Finished in Confinement, with Coffee Hull as Part of the Diet}

\begin{abstract}
The objective of this work was to evaluate the performance of female and male Texel x Bergamacia, Texel x Santa Inês and straitbred Santa Inês. Thirty-six lambs were individually penned for a period of 50 days. The animals were fed elephant grass silage and the following diets: $\mathrm{A}=$ without coffee hulls (control), $\mathrm{B}=$ with untreated in nature coffee hulls and $\mathrm{C}=$ with urea in nature treated coffee hulls and ground soybean seed. The animals were slaughtered with average age of 180 days. The intakes of dry matter (DMI), crude protein $(\mathrm{CP})$, neutral detergent fiber (NDF), feed: gain ratio (F: G), final weight (FW), average daily gain (ADG), slaughter weight (SW), weight loss due to fasting period (FWD), gut content weight (GCW) and empty body weight (EBW) were evaluated. The diets did not affect the intake of DM, CP, FW, SW, FWL, ADG, F: G, GCW and EBW. The neutral detergent fiber intake increased as the coffee hulls increased, and this increase was lower for the animals that consumed diet containing urea treated coffee hulls. The crossbred lambs T x B and T x S showed lower intake of DM, CP and NDF and higher FW, SW, GCW and EBW as compared with straitbreed Santa Inês lambs. There was no difference among the genetic groups for F: G, ADG and FWL, although small high values, but not significant were observed for F: G and ADG of T x B and T x S lambs. The male lambs showed lower DM, CP and NDF and F:G and higher FW, SW, ADW and EBW than the females. The males and females showed similar FWL and GCW.
\end{abstract}

Key Words: feeding, development, genetic group, sheep

\section{Introdução}

A exploração de animais domésticos, como forma de produzir alimento, vem se intensificando como o passar do tempo, mas o desequilíbrio que ainda existe entre a produção de carne e a demanda faz com que haja a necessidade de pesquisas explorando outras espécies animais, além da bovina, suína e aves. A carne ovina, no Brasil, possui baixo consumo, principalmente devido à má qualidade do produto comercializado. Ultimamente, tem-se notado o interesse em intensificar a terminação de cordeiros em

\footnotetext{
${ }^{1}$ Parte do trabalho de Dissertação apresentada pelo primeiro autor como parte das exigências para obtenção do título de Mestre em Zootecnia, pela Universidade Federal de Lavras - Lavras, MG.

2 Doutoranda em Nutrição de Ruminantes - Universidade Federal de Lavras. E.mail: ifurusho@ufla.br

3 Prof. Adjunto da Universidade Federal de Lavras - 37200-000 - Lavras MG. Pesquisador do CNPq. E-mail: jroperez@ufla.br

${ }^{4}$ Prof. Adjunto da Universidade Federal de Lavras. E.mail: jcteixei@ufla.br

${ }^{5}$ Mestranda em Zootecnia - Universidade Estadual Norte Fluminense - UENF.
} 
confinamento, objetivando rapidez para a comercialização e produção de carcaça de melhor qualidade.

O uso de resíduos agro-industriais na alimentação, principalmente em um sistema de confinamento, é de fundamental importância, quando o objetivo é reduzir o custo de produção. A casca de café é um resíduo que apresenta grande potencial de utilização. De acordo com CAIELLI (1984), a casca representa $50 \%$ da produção total de café. A difícil classificação da casca de café como alimento básico útil é mencionada por ROGERSON (1974) e MINARDI et al. (1991), em função da baixa digestibilidade de seus nutrientes, devido principalmente à lignificação do material. BRESSANI et al. (1972) mencionaram que o tratamento alcalino poderia aumentar o uso de polpa de café pelos ruminantes. O uso da uréia no tratamento químico, de acordo com DOLBERG (1992), é de mais fácil manuseio, sendo prático para os pequenos produtores, além de promover a incorporação de nitrogênio não-protéico ao resíduo de baixo valor nutritivo. Segundo GARCIA (1992), com o intuito de melhorar o processo de tratamento químico com uréia, pode-se lançar mão de certos componentes ricos em urease, como o grão de soja, que ajudam a criar, em tempo menor, atmosfera rica em amônia.

Além da alimentação, outros dois fatores de grande importância podem afetar a qualidade da carne de cordeiro: a raça e o sexo (GAILI, 1992). De acordo com SIQUEIRA et al. (1984), o estudo de diversos tipos de cruzamento, nas diferentes condições ambientais das regiões de criação, é fundamental para o desenvolvimento da produção de carne ovina no Brasil. A raça Texel é de origem holandesa e caracteriza-se por ser especializada na produção de carne; destaca-se por sua precocidade e sua carcaça é considerada de excelente qualidade por alguns autores (BONIFACINO et al., 1979; LATIF e OWEN, 1979), principalmente pela menor deposição de gordura. A raça Bergamácia é de origem italiana, inicialmente destinada à produção leiteira. É uma raça com animais de grande porte, destacandose na prolificidade e boa habilidade materna. Após sua introdução no país, adaptou-se bem às variadas condições proporcionada pelas diferentes regiões climáticas do Brasil (SANTOS, 1986). Segundo alguns autores, a raça Santa Inês é proveniente de sucessivos cruzamentos entre as raças Bergamácia e Morada Nova. Caracteriza-se por ser deslanada e de médio a grande porte. Nesta raça, destacam-se a prolificidade, habilidade materna e produção leiteira considerável (SANTOS, 1986). É uma raça de grande importância nacional, devido à sua resistência e capacidade de adaptação à condições adversas de clima, principalmente na região Nordeste, e, mais recentemente, pela distribuição que vem apresentando em outras regiões.

O objetivo deste trabalho foi verificar o desempenho de cordeiros, machos e fêmeas, oriundos dos cruzamentos da raça Texel com as raças Bergamácia e Santa Inês e de cordeiros Santa Inês puros, alimentados com dietas contendo casca de café tratada e não-tratada com uréia e grão de soja moído, terminados em confinamento.

\section{Material e Métodos}

O trabalho foi realizado no Setor de Ovinocultura do Departamento de Zootecnia da Universidade Federal de Lavras, no período de setembro de 1994 a janeiro de 1995.

Foram utilizados 36 animais de três diferentes grupos genéticos, dois provenientes dos cruzamentos de um reprodutor da raça Texel com ovelhas da raça Bergamácia (T x B) e Santa Inês (T x S) e um de animais da raça Santa Inês (SI), filhos de um reprodutor e fêmeas puros. Utilizaram-se 12 cordeiros de cada grupo genético, sendo seis machos e seis fêmeas.

Os cordeiros foram desmamados aos 75 dias de idade média e permaneceram confinados em um único grupo, sendo alimentados com concentrado balanceado e silagem de capim-elefante (Pennisetum purpureum Schum). À idade média de 120 dias, os animais foram confinados em gaiolas individuais de $1,3 \mathrm{~m}^{2}$. Durante o período de adaptação (10 dias), os animais foram vacinados e vermifugados. O período experimental iniciou-se, quando os animais completaram 130 dias de idade média, permanecendo confinados por 50 dias, quando foram abatidos.

As dietas experimentais foram compostas de silagem de capim-elefante (200g/dia) e dos diferentes concentrados (Tabela 1), fornecidos ad libitum: $\mathrm{A}=$ sem casca de café; $\mathrm{B}=$ com casca de café in natura; e $\mathrm{C}=$ com casca de café tratada com $4 \%$ de uréia (peso por peso $[\mathrm{p} / \mathrm{p}]$ da matéria natural $[\mathrm{MN}]$ ) e $1 \%$ [p/p da MN] de grão de soja moído [GSM]). Nesse último tratamento, para facilitar a distribuição uniforme, a uréia foi diluída em quantidade correspondente a $50 \%$ (peso por volume da $\mathrm{MN}$ ) da casca de café a ser tratada. Esta solução foi aspergida na casca, adicionando-se o grão de soja moído, que 
Tabela 1 - Composição percentual dos concentrados utilizados no experimento Table 1 - Percentage composition of the concentrates used in the experiment

\begin{tabular}{|c|c|c|c|}
\hline \multirow[b]{2}{*}{$\begin{array}{l}\text { Ingrediente } \\
\text { Ingredient }\end{array}$} & \multicolumn{3}{|c|}{$\begin{array}{c}\text { Dieta }^{1} \\
\text { Diet }\end{array}$} \\
\hline & A & B & $\mathrm{C}$ \\
\hline $\begin{array}{l}\text { Casca de café in natura } \\
\text { In natura coffee hull }\end{array}$ & ---- & 15,23 & ---- \\
\hline $\begin{array}{l}\text { Casca de café tratada } \\
\text { Treated coffee hull }\end{array}$ & ---- & ---- & 15,27 \\
\hline $\begin{array}{l}\text { Milho desintegrado com palha e sabugo } \\
\text { Corn dehydrated with straw and cob }\end{array}$ & 31,57 & 15,23 & 15,27 \\
\hline $\begin{array}{l}\text { Milho (grão moído) } \\
\text { Corn (grounded grain) }\end{array}$ & 48,72 & 51,70 & 53,23 \\
\hline $\begin{array}{l}\text { Farelo de soja } \\
\text { Soybean meal }\end{array}$ & 14,87 & 13,16 & 11,73 \\
\hline $\begin{array}{l}\text { Farinha de carne e ossos } \\
\text { Meat and bone meal }\end{array}$ & 3,15 & 3,04 & 3,05 \\
\hline $\begin{array}{l}\text { Premix mineral e vitamínico } \\
\text { Mineral and vitamin premix }\end{array}$ & 1,03 & 0,99 & 0,99 \\
\hline $\begin{array}{l}\text { Sal } \\
\text { Salt }\end{array}$ & 0,47 & 0,46 & 0,46 \\
\hline $\begin{array}{l}\text { Uréia } \\
\text { Urea }\end{array}$ & 0,19 & 0,19 & ---- \\
\hline
\end{tabular}

uniformizado e armazenando por três dias, em sacos plásticos pretos, retirando-se o ar. O grão de soja foi utilizado como fonte de urease para que a uréia fosse desdobrada mais rapidamente, liberando a amônia. A casca de café foi moída antes de ser adicionada ao restante dos ingredientes do concentrado; dessa forma, obteve-se uma mistura homogênia, evitando-se a seleção por parte do animais, devido à uniformidade das dietas. As dietas foram isoprotéicas e isoenergéticas (Tabela 2).

Diariamente foram coletadas amostras do concentrado e do volumoso, tanto do fornecido, como das sobras. A dieta foi fornecida de modo que se proporcionasse sobra de 20\%. Posteriormente, prepararam-se amostras compostas semanais, as quais foram submetidas às análises laboratoriais, para determinação de matéria seca (MS), proteína bruta (PB) e fibra em detergente neutro (FDN), de acordo com metodologia citada por SILVA (1981).

Durante o período experimental, os animais foram pesados semanalmente. Decorrido o período de confinamento, os cordeiros foram abatidos, observando-se um período de jejum, de alimento sólido, de 16 horas, registrando-se o peso do animal antes e após o jejum, o peso final (PF) e de abate (PA) e a perda de peso devido ao jejum (PPJ).

Após o abate, realizou-se a evisceração, sendo os órgãos do aparelho digestório pesados cheios e vazios; com a diferença entre estes pesos, obteve-se o peso do conteúdo do aparelho digestório (CAD), o qual, subtraído do peso de abate, permitiu a determinação do peso do corpo vazio (PCV).

O delineamento utilizado foi em blocos casualizados, em um esquema fatorial $3 \times 3 \times 2$ (três dietas, três grupos genéticos e dois sexos). Os animais foram separados em blocos de acordo com o peso ao início do experimento. Os dados foram analisados pelo procedimento GLM do programa estatísticos SAS (1985). Utilizou-se o peso inicial como covariável para análise de todas as variáveis, excluindo para a variável peso inicial, que foi analisada em relação aos grupos genéticos.

As variáveis analisadas neste trabalho foram consumo de matéria seca (CMS), consumo de proteína bruta (CPB), consumo de fibra em detergente neutro (CFDN), peso final (PF), ganho de peso diário (GPD), conversão alimentar (CA), peso de abate (PA), perda de peso devido ao jejum (PPJ), conteúdo do aparelho digestório (CAD) e peso do corpo vazio (PV).

\section{Resultados e Discussão}

\section{Efeito da dieta}

Não houve diferenças significativas entre as dietas para consumo de matéria seca e proteína bruta, indicando que não houve influência do uso da casca 
Tabela 2 - Composição bromatológica dos concentrados, da silagem e da casca de café in natura e tratada, utilizados no experimento (\% na MS)

Table 2 - Chemical composition of the concentrates, silage and coffe hull in natura and treated, used in the experiment (\% of DM)

\begin{tabular}{|c|c|c|c|c|c|c|}
\hline \multirow[b]{2}{*}{$\begin{array}{l}\text { Nutriente } \\
\text { Nutrient }\end{array}$} & \multicolumn{6}{|c|}{$\begin{array}{l}\text { Dieta }^{1} \\
\text { Diet }\end{array}$} \\
\hline & A & B & $\mathrm{C}$ & $\begin{array}{l}\text { Silagem } \\
\text { Silage }\end{array}$ & CCI & CCT \\
\hline Matéria seca & 89,3 & 89,8 & 89,2 & 38,1 & 81,5 & 85,8 \\
\hline $\begin{array}{l}\text { Dry matter } \\
\text { Energia metabolizável* } \\
\text { Metabolizable energy }\end{array}$ & 2.472 & 2.383 & 2.389 & ---- & 1.265 & ---- \\
\hline $\begin{array}{l}\text { Proteína bruta } \\
\text { Crude protein }\end{array}$ & 15,8 & 15,5 & 14,8 & 6,1 & 8,9 & 15,9 \\
\hline $\begin{array}{l}\text { Fibra detergente neutro } \\
\text { Neutral dedetergent fiber }\end{array}$ & 25,8 & 35,3 & 27,8 & 77,6 & 70,5 & 64,4 \\
\hline $\begin{array}{l}\text { Extrato etéreo } \\
\text { Ether extract }\end{array}$ & 4,3 & 4,0 & 3,3 & 2,5 & 3,6 & 3,5 \\
\hline $\begin{array}{l}\mathrm{Ca} \\
\mathrm{P}\end{array}$ & $\begin{array}{l}0,68 \\
0,52\end{array}$ & $\begin{array}{l}0,70 \\
0,48\end{array}$ & $\begin{array}{l}0,76 \\
0,52\end{array}$ & $\begin{array}{l}0,38 \\
0,11\end{array}$ & $\begin{array}{l}0,45 \\
0,17\end{array}$ & $\begin{array}{l}0,52 \\
0,19\end{array}$ \\
\hline
\end{tabular}

de café in natura ou tratada no consumo destes nutrientes (Tabela 3). Resultado semelhante foi encontrado por BARCELOS et al. (1994), para o consumo de matéria seca de novilhos confinados, utilizando casca de café in natura até o nível de $60 \%$.

O consumo de matéria seca encontrado foi relativamente baixo $\left(76 \mathrm{~g} / \mathrm{kg}^{0,75} / \mathrm{dia}\right)$, comparado com valores mencionados nas tabelas de exigências nutricionais para animais desta categoria. O NATIONAL RESEARCH COUNCIL - NRC (1985), por exemplo, cita consumo de $100 \mathrm{~g} / \mathrm{kg}^{0,75} / \mathrm{dia}$ para cordeiros com ganho de peso em torno de $300 \mathrm{~g} / \mathrm{dia}$. Este valor pode ser explicado pelo alto consumo de concentrado em relação ao volumoso (Tabela 3). Outra observação a ser considerada é que os animais não conseguiram atingir o ganho de peso citado pelo NRC (1985), provavelmente por terem potencial de ganho menor que aqueles utilizados na elaboração das tabelas do NRC. O mesmo fato foi observado por BARROS et al. (1994), que também trabalharam com cordeiros Santa Inês puros e cruzas Santa Inês $\mathrm{x}$ Texel, confinados, obtendo valor médio para consumo de matéria seca de $80 \mathrm{~g} / \mathrm{kg}^{0,75} / \mathrm{dia}$.

Verificaram-se diferenças no consumo de fibra em detergente neutro entre as três dietas experimentais $(\mathrm{P}<0,05)$, sendo o consumo maior para os animais que receberam a dieta contendo casca de café in natura e o menor para os que receberam a dieta controle (Tabela 3). Isto pode ser atribuído ao fato de a casca de café ser um resíduo altamente lignificado. A Tabela 2 mostra que a dieta contendo casca in natura foi a que apresentou maior porcentagem de FDN, explicando, dessa forma, o maior consumo observado. O valor de CFDN da dieta contendo casca de café tratada com uréia e GSM foi intermediário entre as outras duas dietas, indicando a ocorrência de quebra da estrutura lignificada em decorrência do tratamento químico, confirmado pelo menor valor determinado para FDN neste tratamento (Tabela 2). CARVALHO et al. (1995) não observaram diferenças no consumo de FDN para cordeiros crioulos, com peso médio inicial de $26,2 \mathrm{~kg}$, confinados por 105 dias, utilizando $15 \%$ de casca de café sem nenhum tratamento químico.

De acordo com os dados apresentados na Tabela 3, não houve diferenças para CA entre as dietas experimentais, ou seja, a utilização da casca de café, tratada ou não, em dietas de cordeiros em confinamento, no nível utilizado, não alterou a conversão alimentar dos animais. No entanto, apesar de não ter ocorrido efeito significativo em nível de 5\%, a dieta contendo casca de café tratada com uréia e grão de soja moído proporcionou menor $\mathrm{CA}$ em relação aos animais que receberam dieta com casca in natura, havendo, possivelmente, melhor aproveitamento da casca de café tratada em relação à in natura, devido à desestruturação da parede celular. Essa possibilidade é reforçada pelo fato de que as 
dietas contendo casca de café têm composição percentual muito semelhantes, no entanto, aquela incluindo a casca tratada apresentou menor valor de FDN (27,8 e 35,3\%) (Tabela 2), que se refletiu na tendência de menor conversão alimentar (Tabela 3). Poder-se-ia cogitar o fato de que apenas a presença da uréia tenha favorecido a obtenção da menor CA, mas todas as dietas foram balanceadas para que apresentassem a mesma quantidade de uréia (Tabela 1), e a quantidade de nitrogênio das mesmas também foi semelhante (Tabela 2).

O ganho de peso diário (GPD) não foi diferente entre os animais que receberam as diferentes dietas (Tabela 3). Contudo, os cordeiros alimentados com a dieta controle obtiveram $17 \mathrm{~g} / \mathrm{dia}$ a mais de GPD $(8,8$ pontos percentuais), que deve ser considerado em um sistema de produção, pois em um período de 50 dias de confinamento seria $850 \mathrm{~g} / \mathrm{animal}$. A média geral de GPD de 199,7 g/dia está abaixo do valor citado por AZZARINI e PONZONI (1979) de 270 g/dia, para produção de carcaça de boa qualidade. Entretanto, os ganhos foram semelhantes aos mencionados por
LATIF e OWEN (1979), $200 \mathrm{~g} /$ dia para cordeiros machos, cruzas Texel x Finn-Dorset, terminados em confinamento.

Déficit de energia nestas dietas pode ter contribuído para menor GPD, além dos genótipos utilizados, que incluíram raças com potencial de ganho provavelmente menor (Bergamácia e Santa Inês) que as raças melhoradoras para a produção de carne, como a Texel, Suffolk ou Ile de France. Também deve ser considerada idade mais avançada dos animais deste experimento, fase em que o ganho de peso normalmente é menor.

A média de peso ao final do período experimental (180 dias de idade média) foi 44,8 kg, não ocorrendo efeito do uso da casca de café, in natura ou tratada, mostrando que é possível a utilização deste resíduo em dietas de cordeiros terminados em confinamento (Tabela 3), sem que haja prejuízos no peso final dos animais.

As dietas não afetaram o peso de abate (PA), sendo a média obtida de 43,8 $\mathrm{kg}$ (Tabela 3), valor superior aos $33 \mathrm{~kg}$ encontrados por LATIF e OWEN (1979), em

Tabela 3 - Valores médios de consumo de matéria seca (CMS), proteína bruta (CPB), fibra em detergente neutro (CFDN), peso inicial (PI), peso final (PF), ganho de peso diário (GPD), conversão alimentar (CA), peso de abate (PA), perda de peso devido ao jejum (PPJ), conteúdo do aparelho digestório (CAD) e peso do corpo vazio (PCV), de acordo com as diferentes dietas experimentais ${ }^{1}$

Table 3 - Mean ( \pm s.e.) intake of dry mater (IDM), crude protein (ICP), neutral detergent fiber (INDF) and mean ( \pm s.e.) of initial weight (IW), final weight ( $F W)$, average daily gain ( $A D G)$, feed:gain $(F G)$, slaughter weight (SW), weight loss due to the fasting period (LDF), gut contents $(G C)$ and empty body weight (EBW), according to different experimental diets ${ }^{1}$

\begin{tabular}{|c|c|c|c|c|c|c|c|}
\hline $\begin{array}{l}\text { Dieta } \\
\text { Diet }\end{array}$ & $\begin{array}{c}\text { Controle } \\
\text { Control } \\
\end{array}$ & Еp & $\begin{array}{c}\text { Casca de café } \\
\text { Coffee hull }\end{array}$ & Ep & $\begin{array}{c}\text { Casca tratada } \\
\text { Treated hul } \\
\end{array}$ & Ep & $\begin{array}{c}\text { Média } \\
\text { Mean }\end{array}$ \\
\hline $\begin{array}{l}\text { CMS }\left(\mathrm{g} / \mathrm{kg}^{0,75} / \mathrm{dia}\right) \\
I D M\end{array}$ & $72,0^{\mathrm{a}}$ & 2,6 & $77,0^{\mathrm{a}}$ & 2,4 & $79,0 \mathrm{a}$ & 2,4 & 76,0 \\
\hline $\begin{array}{l}\text { CPB }\left(\mathrm{g} / \mathrm{kg}^{0}, 75 / \mathrm{dia}\right) \\
\text { ICP }\end{array}$ & $11,0^{\mathrm{a}}$ & 0,38 & $12,0^{\mathrm{a}}$ & 0,36 & $11,0^{\mathrm{a}}$ & 0,36 & 11,3 \\
\hline $\begin{array}{l}\text { CFDN }\left(\mathrm{g} / \mathrm{kg}^{0,75} / \mathrm{dia}\right) \\
\text { INDF }\end{array}$ & $19,0^{c}$ & 0,14 & $29,0^{\mathrm{a}}$ & 0,13 & $24,0^{\mathrm{b}}$ & 0,13 & 24,0 \\
\hline $\begin{array}{l}\mathrm{PI}(\mathrm{kg}) \\
I W\end{array}$ & 36,7 & & 34,4 & & 33,4 & & 34,8 \\
\hline $\begin{array}{l}\mathrm{PF}(\mathrm{kg}) \\
F W\end{array}$ & $47,3^{\mathrm{a}}$ & 1,46 & $44,1^{\mathrm{a}}$ & 1,31 & $43,{ }^{\mathrm{a}}$ & 1,34 & 44,8 \\
\hline $\begin{array}{l}\text { GPD (g/dia) } \\
A D G\end{array}$ & $211,0^{\mathrm{a}}$ & 16,0 & $193,0^{\mathrm{a}}$ & 15,0 & $195,0^{\mathrm{a}}$ & 15,0 & 199,7 \\
\hline $\begin{array}{l}\mathrm{CA}(\mathrm{kg}) \\
F G\end{array}$ & $5,68^{\mathrm{a}}$ & 0,55 & $7,12^{\mathrm{a}}$ & 0,52 & $6,31^{\mathrm{a}}$ & 0,52 & 6,37 \\
\hline $\begin{array}{l}\mathrm{PA}(\mathrm{kg}) \\
S W\end{array}$ & $46,4^{\mathrm{a}}$ & 1,80 & $43,1^{\mathrm{a}}$ & 1,68 & $41,8^{\mathrm{a}}$ & 1,68 & 43,8 \\
\hline $\begin{array}{l}\mathrm{PPJ}(\mathrm{kg}) \\
L D F\end{array}$ & $0,934^{\mathrm{a}}$ & 0,252 & $0,952^{\mathrm{a}}$ & 0,226 & $1,297^{\mathrm{a}}$ & 0,231 & 1,061 \\
\hline $\begin{array}{l}\text { CAD }(\mathrm{kg}) \\
G C\end{array}$ & $4,31^{\mathrm{a}}$ & 0,761 & $4,59^{\mathrm{a}}$ & 0,684 & $4,69^{\mathrm{a}}$ & 0,699 & 4,53 \\
\hline $\begin{array}{l}\mathrm{PCV}(\mathrm{kg}) \\
E B W\end{array}$ & $42,0^{\mathrm{a}}$ & 1,25 & $38,5^{\mathrm{a}}$ & 1,12 & $37,1^{\mathrm{a}}$ & 1,14 & 39,2 \\
\hline
\end{tabular}

1 Médias seguidas de diferentes letras são diferentes pelo teste Tukey $(\mathrm{P}<0,05)$.

Means followed by different letters are different by Tukey test. 
cordeiros confinados e abatidos aos 155 dias.

Não houve diferenças entre as dietas para perda de peso devido ao jejum (PPJ), ou seja, a utilização da casca de café na dieta, independente do tratamento químico, não afetou a perda de peso, que ocorreu no decorrer das 16 horas de jejum alimentar (Tabela 3 ). A média para a PPJ foi $1,1 \mathrm{~kg}$, mostrando que os animais sofreram perda considerável de peso, principalmente os animais que receberam a ração contendo casca tratada $(1,3 \mathrm{~kg})$.

Para o conteúdo do aparelho digestório (CAD), não foi observada diferença entre as dietas experimentais (Tabela 3), o que está de acordo com o resultado encontrado para PPJ, ou seja, provavelmente a utilização da casca de café não fez com que ocorresse diferença no peso do conteúdo digestivo. Conseqüentemente, não houve diferença na variação de peso devido ao jejum entre as dietas. $O$ peso médio encontrado para o CAD foi $4,5 \mathrm{~kg}$, o que representou $10,3 \%$ do peso de abate - valor inferior aos $13,9 \%$ encontrados por ALCADE ALDEA e SIERRA
ALFRANCA (1993), o que talvez seja explicado pelo menor capacidade de retenção de alimento no trato digestivo dos animais do presente experimento. $\mathrm{Ou}$ tro fator que deve ser levado em consideração é o período de jejum adotado no trabalho desses autores. Beranger e Robelin (s.d.), citados por ROHR e DAENICKE (1984), relatam que o conteúdo do trato alimentar pode representar entre 5 a $25 \%$ do peso vivo em bovinos. Os mesmos autores relataram, ainda, que o aumento do peso do conteúdo digestivo está diretamente relacionado com o aumento do consumo de matéria seca.

Efeito do grupo genético

Os grupos genéticos mostraram consumos diferentes $(\mathrm{P}<0,05)$ de matéria seca e proteína bruta (Tabela 4). Os animais cruzados $\mathrm{T}$ x B e $\mathrm{T}$ x S obtiveram consumos de MS e PB semelhantes e menores, enquanto os cordeiros da raça Santa Inês consumiram quantidade maior. Os dados mostram que os animais Santa Inês puros obtiveram menor eficiência em transformar o alimento em produto,

Tabela 4 - Valores médios de consumo de matéria seca (CMS), proteína bruta (CPB), fibra em detergente neutro (FDN), peso inicial (PI), peso final (PF), ganho de peso diário (GPD), conversão alimentar (CA), peso de abate (PA), perda de peso devido ao jejum (PPJ), conteúdo do aparelho digestório (CAD) e peso do corpo vazio (PV), de acordo com o grupo genético ${ }^{1}$

Table 4 - Mean ( \pm s.e.) intake of dry mater (IDM), crude protein (ICP), neutral detergent fiber (INDF) and mean ( \pm s.e.) of initial weight (IW), final weight (FW), average daily gain (ADG), feed:gain (FG), slaughter weight (SW), weight loss due to the fasting period (LDF), gut contents (GC), empty body weight (EBW), by genetic group ${ }^{1}$

\begin{tabular}{|c|c|c|c|c|c|c|c|}
\hline $\begin{array}{l}\text { Cruzamento }^{2} \\
\text { Genetic group }\end{array}$ & $\begin{array}{l}\text { Tx B } \\
T x S\end{array}$ & Ep & $\begin{array}{l}\mathrm{T} \times \mathrm{S} \\
T \times S\end{array}$ & Ep & $\begin{array}{l}\text { SI } \\
\text { SI }\end{array}$ & Ep & $\begin{array}{l}\text { Média } \\
\text { Mean }\end{array}$ \\
\hline $\begin{array}{l}\left.\text { CMS (g/kg }{ }^{0,75} / \mathrm{dia}\right) \\
I D M\end{array}$ & $70,0^{\mathrm{a}}$ & 2,4 & $75,0^{\mathrm{a}}$ & 2,6 & $86,0^{\mathrm{b}}$ & 2,4 & 77,0 \\
\hline $\begin{array}{l}\text { CPB }\left(\mathrm{g} / \mathrm{kg}^{0,75} / \mathrm{dia}\right) \\
\text { ICP }\end{array}$ & $10,0^{\mathrm{a}}$ & 0,35 & $11,0^{\mathrm{a}}$ & 0,38 & $13,0^{\mathrm{b}}$ & 0,35 & 11,3 \\
\hline $\begin{array}{l}\text { CFDN }\left(\mathrm{g} / \mathrm{kg}^{0,75} / \mathrm{dia}\right) \\
I N D F\end{array}$ & $22,0^{\mathrm{a}}$ & 0,13 & $23,0^{\mathrm{ab}}$ & 0,14 & $27,0^{\mathrm{b}}$ & 0,13 & 24,0 \\
\hline $\begin{array}{l}\mathrm{PI}(\mathrm{kg}) \\
I W\end{array}$ & $39,2^{\mathrm{a}}$ & 1,91 & $36,0^{\mathrm{a}}$ & 1,79 & $29,3^{b}$ & 1,79 & 34,8 \\
\hline $\begin{array}{l}\mathrm{PF}(\mathrm{kg}) \\
F W\end{array}$ & $50,4^{\mathrm{a}}$ & 1,64 & $46,4^{\mathrm{a}}$ & 1,33 & $37,6^{\mathrm{b}}$ & 1,61 & 44,8 \\
\hline $\begin{array}{l}\text { GPD }(\mathrm{g} / \text { dia }) \\
A D G\end{array}$ & $224,0^{\mathrm{a}}$ & 15,0 & $208,0^{\mathrm{a}}$ & 16,0 & $166,0^{\mathrm{a}}$ & 15,0 & 199,3 \\
\hline $\begin{array}{l}\mathrm{CA}(\mathrm{kg}) \\
F G\end{array}$ & $5,46^{\mathrm{a}}$ & 0,52 & $6,50^{\mathrm{a}}$ & 0,55 & $7,22^{\mathrm{a}}$ & 0,52 & 6,39 \\
\hline $\begin{array}{l}\mathrm{PA}(\mathrm{kg}) \\
S W\end{array}$ & $49,3^{\mathrm{a}}$ & 1,68 & $45,1^{\mathrm{a}}$ & 1,80 & $36,7^{\mathrm{b}}$ & 1,68 & 43,7 \\
\hline $\begin{array}{l}\mathrm{PPJ}(\mathrm{kg}) \\
L D F\end{array}$ & $1,054^{\mathrm{a}}$ & 0,283 & $1,302^{\mathrm{a}}$ & 0,229 & $0,825^{\mathrm{a}}$ & 0,278 & 1,060 \\
\hline $\begin{array}{l}\mathrm{CAD}(\mathrm{kg}) \\
G C\end{array}$ & $5,28^{a}$ & 0,854 & $5,55^{\mathrm{a}}$ & 0,694 & $2,84^{\mathrm{b}}$ & 0,839 & 4,56 \\
\hline $\begin{array}{l}\mathrm{PCV}(\mathrm{kg}) \\
E B W\end{array}$ & $44,1^{\mathrm{a}}$ & 1,40 & $39,6^{b}$ & 1,14 & $33,9^{c}$ & 1,37 & 39,2 \\
\hline
\end{tabular}

1 Médias seguidas de diferentes letras são diferentes pelo teste de Tukey $(P<0,05)$. Means followed by different letters are different by Tukey test $(P<.05)$.

$2 \mathrm{~T} \times \mathrm{B}=$ Texel $\times$ Bergamácia; T $\times \mathrm{S}=$ Texel $\times$ Santa Inês; $\mathrm{SI}=$ Santa Inês puro.

$T \times B=$ Texel $\times$ Bergamácia; $T \times S=$ Texel $\times$ Santa Inês; $S I=$ pure Santa Inês. 
pois esses animais foram inferiores nos índices de desempenho e consumiram quantidade maior de nutrientes. Observou-se a mesma tendência para o CFDN, sendo que os animais $\mathrm{T}$ x $\mathrm{S}$ tiveram consumo intermediário entre os cruzas T x B e os Santa Inês puros. Por outro lado, isso pode indicar melhor adaptação dos animais Santa Inês para consumo de alimentos fibrosos.

A conversão alimentar média (CA) foi de 6,39, valor semelhante aos relatados por Dansw (1986), citado por SIQUEIRA et al. (1993), e BARROS et al. (1994), os quais relataram conversão alimentar média de 6:1 para cordeiros Santa Inês, abatidos com idade média de 278 dias. Entretanto, é importante salientar que a conversão alimentar média observada por LATIF e OWEN (1980), para cordeiros cruzas, filhos de pai Texel, terminados em confinamento, foi superior (3,6:1). Apesar de não ter ocorrido diferença significativa para grupo genético, os animais cruzados apresentaram CA ligeiramente melhor (Tabela 4). Isso pode indicar a ocorrência de melhor eficiência de utilização do alimento do animais que tiveram a raça Texel como paterna. Segundo SIQUEIRA et al. (1984), cordeiros cruzas oriundos de raça especializada na produção de carne tendem a ser mais exigentes em termos de nutrição, para que possam desenvolver suas potencialidades. Esse fato pode indicar que, no presente trabalho, a energia consumida não tenha atendido às exigências para ganhos mais altos dos animais cruzados.

Não foi verificada diferença em nível de 5\% entre os grupos genéticos, para ganho de peso diário, mas a diferença foi significativa em nível de 6\% (Tabela 4). Os valores médios para ganho de peso mostram que os animais cruzas T x B e T x S (média de $216 \mathrm{~g} / \mathrm{dia}$ ) apresentaram ganhos maiores em relação ao puros (166 g/dia), o que era de se esperar, devido ao ganho genético proporcionado pela utilização da raça Texel no cruzamento. Observou-se superioridade dos dados obtidos em relação aos citados por BARROS et al. (1994), em que cordeiros oriundos de cruzamento entre reprodutor Texel e ovelhas comuns obtiveram ganho médio de $144 \mathrm{~g} /$ dia. Os valores encontrados no presente trabalho também foram superiores aos dados citados por BONIFACINO et al. (1979), que verificaram ganho diário médio de $175 \mathrm{~g} /$ dia para cordeiros machos, cruzas Corriedale x Texel.

Para peso final, os animais Santa Inês puros apresentaram $\mathrm{PF}$ inferior $(\mathrm{P}<0,05)$ aos cordeiros cruzados (Tabela 4). Os animais cruzas T x B e T x S obtiveram média de peso de 48,4 $\mathrm{kg}$ contra $37,6 \mathrm{~kg}$ dos animais Santa Inês puros. O peso inicial (PI) foi comparado entre os diferentes grupos genéticos, considerandose animais com idades semelhantes. Verificaram-se diferenças $(\mathrm{P}<0,05)$ com relação aos grupos genéti$\cos$, indicando peso inferior para os cordeiros Santa Inês puros, explicado pela própria característica da raça e também pelo ganho dos animais cruzas, devido à heterose e à complentariedade ocorrida com a utilização do cruzamento. Estes dados indicam a vantagem da utilização de uma raça especializada como raça paterna, no caso a Texel, objetivando a obtenção de animais que atinjam maior peso de abate mais rapidamente. O peso final médio encontrado por BARROS et al. (1994), $30 \mathrm{~kg}$ para cordeiros cruzas, filhos de pai Texel com ovelhas deslanadas comuns, acima de 200 dias de idade e terminados em confinamento, foram inferiores aos observados neste trabalho.

Houve diferenças entre os grupos genéticos $(\mathrm{P}<0,05)$ para o peso de abate, com superioridade para os cordeiros cruzas $\mathrm{T} \times \mathrm{B}$ e $\mathrm{T} \times \mathrm{S}$, os quais apresentaram, respectivamente, pesos médios de 49,3 e $45,1 \mathrm{~kg}$, enquanto os animais SI mostraram peso médio de $36,7 \mathrm{~kg}$ (Tabela 4). Isso indica uma das vantagens da utilização do cruzamento industrial, principalmente quando se usa uma raça especializada na produção de carne, com animais das raças Santa Inês e Bergamácia.

A perda de peso devido ao jejum (PPJ) não foi afetada pelos grupos genéticos (Tabela 4). Para PPJ, foram observados erros-padrão elevados (Tabelas 3, 4 e 5), indicando que houve variação alta entre os animais neste experimento, o que impossibilita a obtenção de conclusões mais precisas.

Observaram-se diferenças $(\mathrm{P}<0,05)$ entre os grupos genéticos (Tabela 4) para o conteúdo do aparelho digestivo (CAD). O peso do conteúdo foi nitidamente inferior para os cordeiros Santa Inês puros, representando 7,7\% do peso de abate destes animais. Para os cordeiros cruzas T x B e T x SI, essa porcentagem em relação ao peso de abate foi, respectivamente, $10,7 \mathrm{e}$ $12,3 \%$. Isso mostra que os animais cruzas, apesar de terem apresentado menor consumo de matéria seca, obtiveram maior peso de conteúdo digestivo no momento do abate. Esse maior peso pode ser atribuído à maior quantidade de líquidos presente no aparelho digestório dos animais cruzas em relação aos animais SI, considerando que esses últimos obtiveram maior CMS. Essa diferença pode significar diferenças na capacidade de retenção de alimento entre os genótipos utilizados, que pode resultar em valores de digestibilidade também diferentes. Por outro lado, esta diferença confirma a observação de KREMER et al. (1979), resultando na importância cada vez maior do conteúdo digestivo sobre o peso total do animal e sua implicação com o rendimento da carcaça e seu reflexo na valorização no momento da venda. 
Foram observadas diferenças significativas $(\mathrm{P}<0,05)$ para PCV entre os grupos genéticos (Tabela 4). Os cordeiros $\mathrm{T}$ x B apresentaram pesos superiores $(44,1 \mathrm{~kg})$ aos cruzas T x SI $(39,6 \mathrm{~kg})$, os quais foram superiores aos valores apresentados pelos cordeiros SI $(33,9 \mathrm{~kg})$. Estes dados concordam com os obtidos para conteúdo digestivo e mostram a superioridade de animais provenientes de cruzamentos industriais, utilizando raças especializadas.

\section{Efeito do sexo}

As fêmeas apresentaram CMS, CPB e CFDN significativamente maiores $(\mathrm{P}<0,05)$ em relação aos machos (Tabela 5), o que se deve ao metabolismo diferenciado entre machos e fêmeas. De acordo com ORSKOV (1990), a quantidade de alimento consumido pelo animal é determinada pela sua capacidade de metabolizar os nutrientes, a qual é influenciada pelos hormônios sexuais.

Houve diferenças significativas $(\mathrm{P}<0,05)$, indicando melhor CA para os machos e superioridade dos mesmos no valores de GPD, PF, PA e PCV, o que pode ser explicado pela influência de hormônios sexuais, que afeta, principalmente, o metabolismo do nitrogênio (HAFEZ, 1972) e, conseqüentemente, a composição do ganho e o desenvolvimento corporal, notadamente verificado pelos dados apresentados (Tabela 5). Com relação ao peso vazio, ALCALDE ALDEA e SIERRA ALFRANCA (1993) relataram, em seu trabalho, que a superioridade dos machos em relação às fêmeas também pode ser explicada pelo desenvolvimento precoce de componentes corporais e órgãos internos nas fêmeas. Portanto, os machos que apresentaram desenvolvimento tardio em relação às fêmeas obtiveram maior peso vazio, considerando-se a idade em que foram sacrificados.

Também não foi observada diferença entre o sexos (Tabela 5) para DPJ e CAD, apesar de ter ocorrido pequena superioridade dos machos em maior nível de significância para o último parâmetro. Contudo, considerando-se que os pesos do CAD não foram diferentes, confirma-se a melhor conversão alimentar dos machos, que apresentaram melhor desempenho.

Tabela 5 - Valores médios de consumo de matéria seca (CMS), proteína bruta (CPB), fibra em detergente neutro (FDN), peso inicial (PI), peso final (PF), ganho de peso diário (GPD), conversão alimentar (CA), peso de abate (PA), perda de peso devido ao jejum (PPJ) conteúdo do aparelho digestivo (CAD) e peso do corpo vazio (PCV), de acordo com o sexo ${ }^{1}$

Table 5 - Average ( \pm s.e.) intake of dry mater (IDM), crude protein (ICP), neutral detergent fiber (INDF) ( \pm s.e.) initial weight (IW), final weight (FW), average daily gain ( $A D G)$, feed:gain ratio (FG), slaughter weight $(S W)$, weight loss due to the fasting period (LDF), gut contents (GC) and empty body weight (EBW), by sex $^{1}$

\begin{tabular}{|c|c|c|c|c|c|}
\hline $\begin{array}{l}\text { Sexo } \\
\text { Sex }\end{array}$ & $\begin{array}{l}\text { Macho } \\
\text { Male }\end{array}$ & Ep & $\begin{array}{l}\text { Fêmea } \\
\text { Female }\end{array}$ & Ep & $\begin{array}{l}\text { Média } \\
\text { Mean }\end{array}$ \\
\hline $\begin{array}{l}\text { CMS }\left(\mathrm{g} / \mathrm{kg}^{0,75} / \mathrm{dia}\right) \\
\text { IDM }\end{array}$ & $71,0^{\mathrm{a}}$ & 2,1 & $91,0^{\mathrm{b}}$ & 2,0 & 76,0 \\
\hline $\begin{array}{l}\text { CPB }\left(\mathrm{g} / \mathrm{kg}^{0,75} / \mathrm{dia}\right) \\
\text { ICP }\end{array}$ & $11,0^{\mathrm{a}}$ & 0,3 & $12,0^{\mathrm{b}}$ & 0,3 & 11,5 \\
\hline $\begin{array}{l}\text { CFDN }\left(\mathrm{g} / \mathrm{kg}^{0,75} / \mathrm{dia}\right) \\
\text { INDF }\end{array}$ & $22,0^{\mathrm{a}}$ & 0,1 & $26,0^{\mathrm{b}}$ & 0,1 & 24,0 \\
\hline $\begin{array}{l}\mathrm{PI}(\mathrm{kg}) \\
I W\end{array}$ & $37,9^{\mathrm{a}}$ & 1,52 & $31,8^{\mathrm{b}}$ & 1,46 & 34,9 \\
\hline $\begin{array}{l}\mathrm{PF}(\mathrm{kg}) \\
F W\end{array}$ & $49,5^{\mathrm{a}}$ & 1,27 & $40,2^{\mathrm{b}}$ & 1,18 & 44,9 \\
\hline $\begin{array}{l}\mathrm{GPD}(\mathrm{g} / \mathrm{dia}) \\
A D G\end{array}$ & $232,0^{\mathrm{a}}$ & 12,8 & $168,0^{\mathrm{b}}$ & 12,3 & 200,0 \\
\hline $\begin{array}{l}\mathrm{CA}(\mathrm{kg}) \\
F G\end{array}$ & $5,36^{\mathrm{a}}$ & 0,44 & $7,37^{\mathrm{b}}$ & 0,42 & 6,36 \\
\hline $\begin{array}{l}\mathrm{PA}(\mathrm{kg}) \\
S W\end{array}$ & $48,4^{\mathrm{a}}$ & 1,44 & $39,2^{\mathrm{b}}$ & 1,37 & 43,8 \\
\hline $\begin{array}{l}\mathrm{PPJ}(\mathrm{kg}) \\
L D F\end{array}$ & $1,124^{\mathrm{a}}$ & 0,219 & $0,998^{\mathrm{a}}$ & 0,204 & 1,061 \\
\hline $\begin{array}{l}\mathrm{CAD}(\mathrm{kg}) \\
G C\end{array}$ & $4,78^{\mathrm{a}}$ & 0,661 & $4,31^{\mathrm{a}}$ & 0,616 & 4,54 \\
\hline $\begin{array}{l}\mathrm{PCV}(\mathrm{kg}) \\
E B W\end{array}$ & $43,6^{\mathrm{a}}$ & 1,08 & $34,9^{\mathrm{b}}$ & 1,01 & 39,3 \\
\hline
\end{tabular}

Médias seguidas de diferentes letras são diferentes pelo teste Tukey $(P<0,05)$.

Means followed by different letters are different by Tukey test $(P<.05)$ 


\section{Conclusões}

O uso de casca de café, em nível de $15 \%$, em dietas de cordeiros terminados em confinamento, não afetou o desempenho dos animais.

A utilização da casca de café in natura proporcionou maior consumo de FDN.

Os animais provenientes do cruzamento industrial, utilizando a Texel como raça paterna, obtiveram desempenho melhor em comparação aos animais Santa Inês puros.

Os machos apresentaram desempenho superior ao das fêmeas.

\section{Referências Bibliográficas}

ALCALDE ALDEA, M.J., SIERRA ALFRANCA, I. 1993. Acabado de cordeiros merinos extremeños en cebadero: pesos, crecimientos, rendimientos y valor del quinto cuarto. Archivos de Zootecnia, 42(157):161-172.

AZZARINI, M., PONZONI, R. 1979. Aspectos modernos de la produción ovina. Montevideo: Universidade de la Republica. Departamento de Publicaciones. 75p.

BARCELOS, A.F., ANDRADE, I.F., TIESENHAUSEN, I.M.E.V. von. et al. Aproveitamento da casca de café na alimentação de novilhos confinados. 1- Resultados técnicos do segundo ano. In: REUNIÃO ANUAL DA SOCIEDADE BRASILEIRA DE ZOOTECNIA, 31, 1994, Maringá. Anais... Maringá: SBZ, 1994, p.457.

BARROS, N.N., FIGUEIREDO, E.A.P., FERNANDES, F.D. et al. 1994.Ganho de peso e conversão alimentar de cordeiros cruzas no estado do Ceará. Pesq. Agropec. Bras., 29(8):1313-1317.

BONIFACINO, L., KREMER, R., LARROSA, J. et al. 1979. Estudio comparativo de corderos Corriedale y Corriedali $\mathrm{x}$ Texel. (III) Pesos al nacer, ganancias diárias y caracteristicas de las carcasas a los 109 dias. Veterinaria, 71:123-131.

BRESSANI, R., ESTRADA, E., JARQUÍN, R. 1972. Pulpa y pergamino de café. I. Composición química y contenido de aminoácidos de la proteina de la pulpa. Turrialba, 22(3): 299-304.

CAIELLI, E.L.1984. Uso da palha de café na alimentação de ruminantes. Inf. Agropec., 10(119):36-38.

CARVALHO, F.F.R.C., FERREIRA, J.Q., CONCEIÇÃO, J.R.V. da. Uso da casca de café na alimentação de ovinos em crescimento. In: REUNIÃO ANUAL DA SOCIEDADE BRASILEIRA DE ZOOTECNIA, 32, Brasília, 1995. Anais... Brasília: SBZ, 1995, p.181-183.

DOLBERG, F. Progressos na utilização de resíduos de culturas tratados com uréia-amônia: implicaões nutricionais e aplicações de tecnologia em pequenas propriedades. In: SIMPÓSIO INTERNACIONAL DE RUMINANTES, Lavras, 1992. Anais... Lavras: SBZ, 1992, p.322-337.

GAILI, E.S.E. 1992. Breed and sex differences in body composition of sheep in relation to maturity and growth rate. J. Agric. Sci., 118(1):121-126.
GARCIA, R. Amonização de forragens de baixa qualidade e a utilização na alimentação de ruminantes. In: SIMPÓSIO DE UTILIZAÇÃO DE SUBPRODUTOS AGROINDUSTRIAIS E RESÍDUOS DE COLHEITA NA ALIMENTAÇÃO DE RUMINANTES, 1, São Carlos, 1992. Anais... São Carlos: EMBRAPA-UEPAE, 1992, p.83-98.

HAFEZ, E.S.E., DYER, E.A. 1972. Desarrolo y nutrición animal. Zaragoza: Acribia. 472p.

KREMER, R., ORLANDO, D., SIENRA, I. et al. 1979. Estudio comparativo de Corriedale y Corriedale x Texel. I. Pesos al nascer. Ganancias diarias. Curvas de crecimiento. Veterinaria, 69:13-18.

LAFIT, M.G.A., OWEN, E. 1979. Comparison of Texel and Suffolk sired lambs out of Finnish Landrace x Dorset Horn ewes under grazing conditions. J. Agric. Sci., 93(1):235-239.

LAFIT, M.G.A., OWEN, E. 1980. A note on the growth performance and carcass composition of Texel and Suffolk sired lambs in a intensive system. Anim. Prod., 30(2):311-314.

MINARDI, I., BONA FILHO, A., SOUZA, G.A. et al. 1991. Determinação do valor nutritivo do resíduo de malte, casca de café e da raspa de mandioca através de ensaios de digestibilidade "in vivo" com ovinos. Revista do Setor de Ciências Agrárias, 11(2):135-143.

NATIONAL RESEARCH COUNCIL - NRC. 1985. Nutrient requeriments of sheep. New York: National Academy Press. 99p.

ORSKOV, E.R. 1990. Alimentación de los rumiantes. Princípios y práctica. Zaragoza: Acribia. 119p.

ROGERSON, A. Nutritive value of coffee hulls. IN: UTILIZACIÓN DE SUBPRODUCTOS DEL CAFÉ EN LA ALIMENTACIÓN ANIMAL Y OTRAS APLICACIONES AGRICOLAS E INDUSTRIALES, Turrialba, 1974. Bibliografia Anotada... Turrialba: Centro Agronomico Tropical de Investigación y Enseñanza, 1974, p.5.

ROHR, K., DAENICKE, R. 1984. Nutritional effects on the distribution of live weight as gastrointestinal tract fill and tissue components in growing cattle. J. Anim. Sci., 58(3):753-765.

SANTOS, V.T. 1986. Ovinocultura. Princípios básicos para sua instalação exploração. São Paulo: Nobel. 167p.

SAS - Institute. SAS User's guide: Statistics. 5. ed. Cary, 1985. 956p.

SILVA, D.J. 1981. Análise de alimentos (Métodos químicos e biológicos). Viçosa: UFV. 165p.

SIQUEIRA, E.R., AMARANTE, A.F.T., FERNANDES, S. 1993. Estudo comparativo da recria de cordeiros em confinamento e pastagem. Veterinária e Zootecnia, 5:17-28.

SIQUEIRA, E.R., OSÓRIO, J.C.S., GUERREIRO, J.L.V. et al. 1984. Desempenho de cordeiros machos e fêmeas da raça Ideal e cruzas Texel x Ideal, criados em pastagem nativa. Pesq. Agropec. Bras., 19:1523-1528.

Recebido em: $24 / 08 / 98$

Aceito em: 21/09/99 